American Journal of Pharmaceutical Education 2020; 84 (3) Article 7547.

\title{
RESEARCH
}

\section{Patterns of Stress, Coping and Health-Related Quality of Life in Doctor of Pharmacy Students}

\author{
Jan D. Hirsch, PhD, BSPharm, ${ }^{\text {a,b }}$ Poorva Nemlekar, MS, BSPharm, ${ }^{\mathrm{b}}$ Patrick Phuong, PharmD, \\ Kathryn A. Hollenbach, PhD, ${ }^{b}$ Kelly C. Lee, PharmD, MAS, ${ }^{\mathrm{b}}$ David S. Adler, PharmD, ${ }^{\mathrm{b}}$ \\ Candis M. Morello, PharmD \\ ${ }^{a}$ University of California Irvine, Pharmaceutical Sciences, Irvine, California \\ ${ }^{\mathrm{b}}$ University of California San Diego, Skaggs School of Pharmacy and Pharmaceutical Sciences, La Jolla, California \\ Submitted February 6, 2019; accepted August 27, 2019; published March 2020.
}

\begin{abstract}
Objective. To examine perceived stress, coping strategies, and health-related quality of life in Doctor of Pharmacy students across the first three years (pre-clinical portion) of the curriculum.

Methods. Three instruments, the Perceived Stress Scale, Brief COPE, and Short Form-36, were administered to students three times a year over a five-year period. Median annual scores were compared using Skillings-Mack tests and correlations were assessed using Spearman correlation.

Results. One hundred forty-five students (approximately 46\% of the school's enrollment) participated. A significant increase in scores on the PSS, increase in students' maladaptive coping behaviors, and worsening mental health-related quality of life were detected in students across the first three years of the pre-clinical curriculum. The PSS scores of first- and second-year pharmacy students had a moderate to large positive correlation with maladaptive coping behaviors (rho $=0.43$ and 0.58 , respectively) and PSS scores exhibited a large negative correlation with maladaptive coping behaviors in all three years of the pre-clinical curriculum (rho ranged from -0.69 to -0.78 ).

Conclusion. Increasing levels of stress, increasing use of maladaptive coping strategies, and declining mental health-related quality of life among pharmacy students across the first three years of the fouryear curriculum were very similar to findings in the cohort of pharmacy students observed in the preceding five years.
\end{abstract}

Keywords: doctor of pharmacy students, perceived stress, coping strategies, adaptive coping, maladaptive coping, health-related quality of life

\section{INTRODUCTION}

The rigor of achieving an advanced degree is commonly accompanied by feelings of stress, particularly in the ever growing and changing field of health sciences. Stress can disrupt the student learning experience. How students handle stress is largely dependent on their personal coping strategies and self-care. College administrators and faculty members must evaluate students' stress, coping methods, and quality of life to help identify issues that are negatively affecting students and strategize solutions and preventative methods.

Many studies have assessed stress experienced by Doctor of Pharmacy (PharmD) students within US pharmacy schools. ${ }^{1-7}$ These studies have reported that higher stress levels are associated with greater fear of debt, ${ }^{1}$ greater use of maladaptive coping strategies, ${ }^{2}$ and poorer

Corresponding Author: Jan D. Hirsch, University of California Irvine, 101 Theory, Ste. 100, Irvine, CA 92612. Tel: 949-824-0505. Email: jdhirsch@uci.edu academic self-concept. ${ }^{7}$ Higher stress levels have been observed in the academic years following the first PharmD year, ${ }^{2,}$ students with lower exercise frequency, ${ }^{2}$ female students, ${ }^{4,5}$ students younger than 22 years and older than 32 years, ${ }^{4}$ direct-entry programs compared to two/four or postgraduate programs, ${ }^{5}$ Asian students compared to Caucasian students, ${ }^{5}$ students with lower grade point averages, ${ }^{5,6}$ and students reporting a high level of mentally unhealthy days. ${ }^{6}$ Increased stress has also been cited as one of the top three motivations for pharmacy student cheating. ${ }^{3}$ All of the aforementioned studies were cross-sectional, relying on a single assessment of stress at one time point within a given curriculum. These single measures may not be representative of overall stress in a PharmD student population because of the episodic nature of common stressors for students, such as examinations, assignments, and class load, which may vary across quarters or semesters. A single published study with multiple assessments of stress throughout the 


\section{American Journal of Pharmaceutical Education 2020; 84 (3) Article 7547.}

curriculum years revealed that, stress was significantly higher during the second vs the first year of pharmacy school. The study showed that increased stress in PharmD students in all years of the curriculum was associated with lower mental health-related quality of life (HRQOL) scores and greater use of maladaptive coping strategies. ${ }^{8}$

Because of the growing evidence of increased stress and negative outcomes in PharmD students, there has been an increased impetus within pharmacy education for measuring student stress, wellness, and coping behaviors. The American Association of Colleges of Pharmacy (AACP) Student Affairs Standing Committee recommended in 2017 that pharmacy schools expand efforts to increase awareness and monitoring of student wellness and urged schools to promote wellness and stress management techniques to students, and faculty and staff members. ${ }^{9}$ Additionally, recently revised Accreditation Council for Pharmacy Education (ACPE) accreditation standards for PharmD programs require schools to be appropriately staffed and resourced to develop, implement, and assess policies and procedures that promote student success and well-being (Standard 14: Student Services, Guidance Standard 24e of ACPE Standards 2016). Standards 2016 require that schools measure perceived stress in students and evaluate the potential negative impact that stress may have on programmatic outcomes and morale. ${ }^{10}$

The purpose of this study was to explore whether the patterns of stress, coping, and HRQOL previously observed in a cohort of PharmD students in the beginning years of a new school of pharmacy ${ }^{8}$ persisted in the following five years among a second cohort of PharmD students attending the same school after the program was more established. Student experiences for the first cohort in the early years of the school may have been more stressful because of the evolving curriculum, student life, career uncertainty, and less-experienced school administration. In addition, guided by results from the first cohort study as well as other data and feedback from students, changes were made at the pharmacy school. Thus the experience of students in later years may have been very different. The specific objectives of this study were to examine the perceived stress, coping strategies, and HRQOL of students across the three pre-clinical curriculum years of the PharmD program, and to examine relationships among perceived stress, coping strategies, and HRQOL in this second cohort of students.

\section{METHODS}

This study was an extension of an ongoing cohort study that started in the academic year 2004-2005. ${ }^{8}$ Approval for this study was received from and renewed by the University of California San Diego (UCSD) Human
Research Protection Program, which had approved the first study. All participating study subjects provided informed consent. The second study took place during academic years 2009-2010 through 2013-2014. The first opportunity for incoming first-year pharmacy students to complete the survey was during orientation, which was conducted during the week prior to the beginning of class.

All surveys were conducted using SurveyMonkey (Palo Alto, CA). During the five years of the study, a link to the survey instrument was sent electronically to all students enrolled in the first, second, and third professional (P1, P2, and $\mathrm{P} 3$, respectively) years of the PharmD program at the middle of the fall, winter, and spring quarters. Participation in this study was voluntary. Students who had not enrolled in the study during their P1 orientation could enroll and provide informed consent when completing any of the subsequent surveys. A student's data were used only if the student had provided informed consent. Subjects were assured that all responses were confidential and would be reported as aggregate data in the study results. As an incentive to participate, each quarter a lottery drawing for a $\$ 50$ bookstore gift card was held using student study identifier numbers.

Three validated instruments were included in the survey to collect study data regarding students' perceived stress, coping strategies, and HRQOL. A 10-item version of the Perceived Stress Scale (PSS) was used to measure stress (Appendix 1). ${ }^{11}$ The PSS is a self-administered questionnaire that measures the degree of perceived stress in situations. The items relate to how unpredictable, uncontrollable, and overloaded respondents find their lives in general and do not focus on a specific event. Questions about how often certain feelings or thoughts have occurred in the past four weeks are measured on a five-point Likert type response scale with responses ranging from never to very often. The PSS was chosen because there are comparative values in the literature and it is not specific to a particular type of stress. A total perceived stress score was calculated, with higher values indicating a greater level of stress (score converted to 0 to 100 scale in this study to facilitate interpretation).

The Brief COPE measured coping strategies, ie, how much an individual used both adaptive and maladaptive coping strategies on a scale of 1 ('I haven't been doing this at all') to 4 ('I've been doing this a lot') (Appendix 2). ${ }^{12,13}$ Adaptive strategies have been cited as being related to desirable outcomes and maladaptive strategies with less favorable outcomes. ${ }^{14}$ An adaptive coping score ranging from 16 to 64 was derived from the sum of responses across the 16 items related to adaptive coping strategies and a maladaptive score ranging from 12 to 48 was derived from sum of responses across the 12 items related to maladaptive strategies. Each of these scores was 


\section{American Journal of Pharmaceutical Education 2020; 84 (3) Article 7547.}

converted to a 0 to 100 scale to facilitate interpretation. Higher scores indicate greater use of that particular type of coping strategy.

Students' HRQOL was measured using the Optum SF$36 v 2$ Health Survey (SF-36), version two. ${ }^{15}$ The SF-36 is a self-administered, widely used general health instrument consisting of 36 items. Each item measures eight domains of physical and mental health. A physical component summary (PCS) and a mental component summary (MCS) score were calculated, with higher scores indicating better health status. Scores were normalized to the US general population, with a mean score $=50 \pm 10$ allowing comparison to published US norms and to results reported in the literature, including those reported for PharmD students.

Any subject with $50 \%$ or greater missing data on a scale or instrument was excluded from the study. If less than $50 \%$ of responses were missing, the mean of the remaining items on the scale was used as an imputed value.

Demographic data (age, gender and ethnicity) were collected during the initial survey administered, (ie, administered during the $\mathrm{P} 1$ orientation session or subsequently if the subject joined the study later). Descriptive statistics for all variables were calculated. Shapiro Wilks tests and scatter plots were examined to assess normality of data distribution. Average annual scores (average of a student's data for the quarters for which a completed questionnaire was available during the first three pre-clinical years) were calculated for the PSS, Maladaptive and Adaptive coping, PCS, and MCS. Because multiple classes of students were enrolled over the five academic years of the study, an analysis of variance (ANOVA) was first conducted to compare mean scores on the PSS, Maladaptive and Adaptive coping, PCS, and MCS among classes of students in each of the three professional years to determine if there were significant differences in the experience (mean scores) between classes of students. This analysis indicated no significant differences between classes for all variables in all professional years except for one variable for the class of 2014 in one year. This difference was deemed minor; thus, data for all students (regardless of class) enrolled in a specific curricular year (P1, P2 or P3) were combined for subsequent analyses of PSS, Maladaptive and Adaptive coping, PCS, MCS by curricular year.

Skillings-Mack tests were used to compare median scores (PSS, Maladaptive and Adaptive coping, PCS, MCS) across the four assessment periods (Pre-P1-P3). Post-hoc Skillings-Mack tests were used to test two-way comparisons between individual years when the result of the initial Skillings-Mack test was significant.

A five-point difference (one-half the standard deviation) in mean norm-based PCS and MCS scores was considered meaningful. ${ }^{16}$ The relationships between PSS, Maladaptive and Adaptive coping, PCS, and MCS were

assessed using the Spearman correlation. Correlations of 0.29 or less were considered to be small, those between 0.30 and 0.49 were considered moderate, and those greater or equal to 0.5 were considered large. ${ }^{17}$ Statistical analyses were conducted using STATA, 15.0 (College Station, TX). Significance levels were set a priori at 0.05 for initial comparisons and 0.01 for post hoc testing.

\section{RESULTS}

Of the 313 eligible students during the study period (classes of 2013 to 2017), 145 (46.3\%) provided consent and were enrolled in the study. Descriptive statistics are presented in Table 1 . The majority of subjects were female $(73.8 \%)$ and 25 years of age or less $(80.0 \%)$. The largest proportion of subjects (69.7\%) were Asian/Pacific Islander followed by White/Caucasian (23.5\%). Descriptive characteristics were similar to that of the student body. Enrollment by class ranged from $35.7 \%$ (class of 2016 ) to $63.2 \%$ (class of 2013) and is depicted in Table 2.

A significant difference in median PSS score was detected across assessments for the P1, P2, and P3 years $(p=.0003)$ (Table 3$)$. The median level of stress reported in by P1, P2, and P3 students was significantly greater than reported by students at entry to pharmacy school (41.1, 46.3 , and 51.3 vs 35.0 , respectively, all $p$ values $<.01$ ). There was a significant difference in median maladaptive coping strategies detected across the P1, P2, and P3 years

Table 1. Descriptive Characteristics of Subjects $(n=145)$

\begin{tabular}{lc}
\hline Variable & No. $(\mathbf{\%})^{\mathbf{a}}$ \\
\hline Gender & \\
Female & $107(73.8)$ \\
Male & $36(24.8)$ \\
Missing & $2(1.4)$ \\
Age, years & \\
$\leq 25$ & $116(80.0)$ \\
$>25$ & $29(20.0)$ \\
Graduating class year (entering class size) & \\
2013 (n=57) & $36(24.8)$ \\
$2014(\mathrm{n}=60)$ & $33(22.8)$ \\
$2015(\mathrm{n}=57)$ & $22(15.2)$ \\
$2016(\mathrm{n}=56)$ & $20(13.8)$ \\
$2017(\mathrm{n}=60)$ & $34(23.5)$ \\
Ethnicity & \\
White/Caucasian & $34(23.5)$ \\
Black/African - American & $1(0.7)$ \\
Asian/Pacific Islander & $101(69.7)$ \\
American Indian & $1(0.7)$ \\
Latino/Hispanic & $3(2.1)$ \\
Other & $2(1.4)$ \\
Missing & $3(2.1)$ \\
\hline May not sum to $100 \%$ due to rounding
\end{tabular}




\section{American Journal of Pharmaceutical Education 2020; 84 (3) Article 7547.}

Table 2. Participation by Graduating Class Year

\begin{tabular}{lcrrr}
\hline Class & Pre-P1 $^{\text {a }}$ & P1 & P2 & P3 \\
\hline 2013 & 36 & 30 & 25 & 18 \\
2014 & 33 & 38 & 28 & 21 \\
2015 & 22 & 21 & 12 & 8 \\
2016 & 20 & 7 & 1 & NA \\
2017 & 34 & 25 & NA & NA \\
Total $^{\text {b }}$ & 145 & 121 & 66 & 47 \\
\hline
\end{tabular}

${ }^{\mathrm{a}}$ Pre-P1 = Pre Curriculum Year One, P1 =Curriculum Year One, $\mathrm{P} 2=$ Curriculum Year Two, P3 = Curriculum Year Three

${ }^{\mathrm{b}}$ Not all subjects participated each curriculum year

$\mathrm{NA}=$ Not Available since students had not progressed to curriculum year at time of data collection

$(p<.001)$ (Table 3). The median maladaptive coping scores were significantly higher in the P1, P2, and P3 years than that median scores at entry to pharmacy school (32.9, 33.6 , and 35.0 vs 16.7 , respectively, all $p$ values $<.01$ ). Students' median adaptive coping strategies differed across the three years of the curriculum $(p=.02)$. Although none of the individual post hoc comparisons between years was significant, a trend of lower adaptive coping strategies was observed as students progressed through each year of the curriculum.

Median PCS and MCS scores (56.5 and 48.6, respectively) of $\mathrm{P} 1$ students at orientation were similar to the mean age-adjusted US norms (PCS, 53.5; MCS, 49.2). A significant difference in median MCS scores $(p<.001)$, but not PCS scores $(p=.8870)$, was detected across the three years of the curriculum. (Table 3). The median MCS scores were significantly lower, indicating the mental health condition of students was worse in the P1, P2, and P3 years than reported at entry to pharmacy school $(41.3,36.3$, and 34.6 vs 48.6 , respectively, all $p$ values $<.01$ ). Also, the median MCS score for P3 students was significantly lower than the median score for P1 students (34.6 vs 48.6, $p<.01$ ). The magnitude of difference in median MCS scores was greater than the five-point difference considered clinically significant in the $\mathrm{P} 1$ year vs pre-P1 year and more than twice that in the $\mathrm{P} 2$ and $\mathrm{P} 3$ years vs the $\mathrm{P} 1$ year.

Perceived stress exhibited significant correlations with maladaptive coping strategies (higher stress/greater use of maladaptive coping) in Pre-P1 students ( $\mathrm{rho}=0.43$, $p<.0001), \mathrm{P} 1$ students $(\mathrm{rho}=0.24, p=.02)$ and $\mathrm{P} 2$ students (rho $=0.58, p<.001$ ) (Table 4). Among P3 students, perceived stress had a moderate negative correlation with use of adaptive coping strategies (higher stress/lower use of adaptive coping, rho $=-0.31, p=.04)$. A moderate to large negative correlation was detected between perceived stress and MCS scores in all three years of the curriculum (higher stress/lower MCS, rho $=-0.47$ to -0.78 , all $p$ values $<.001)$.

\section{DISCUSSION}

The results of this study revealed that PharmD students at this school experienced increased levels of stress, poorer

Table 3. Perceived Stress, Coping Strategies, and Health-Related Quality of Life of Doctor of Pharmacy Students by Curriculum Year

\begin{tabular}{|c|c|c|c|c|c|}
\hline \multirow{3}{*}{$\begin{array}{l}\text { Median } \\
\left(25^{\text {th }}, 75^{\text {th }}\right)(n) \\
\text { Curriculum } \\
\text { Year }^{\text {d }}\end{array}$} & \multirow{3}{*}{$\begin{array}{c}\text { PSS }^{\mathbf{a}} \\
\text { Perceived } \\
\text { Stress Scale }\end{array}$} & \multicolumn{2}{|c|}{ Brief COPE $^{b}$} & \multirow{2}{*}{\multicolumn{2}{|c|}{ HR-QOL $^{c}$}} \\
\hline & & \multirow{2}{*}{$\begin{array}{c}\text { Maladaptive Coping } \\
\text { Strategies }\end{array}$} & \multirow{2}{*}{$\begin{array}{c}\text { Adaptive Coping } \\
\text { Strategies }\end{array}$} & & \\
\hline & & & & $(\mathrm{PCS})^{\mathrm{e}}$ & $(\mathrm{MCS})^{\mathrm{f}}$ \\
\hline Pre-P1 & $\begin{array}{c}35(22.5,42.5) \\
\quad(141)\end{array}$ & $\begin{array}{l}16.7(8.3,27.8) \\
(135)\end{array}$ & $\begin{array}{l}59(37.5,62.5) \\
(135)\end{array}$ & $\begin{array}{c}56.5(52.5,59.2) \\
(139)\end{array}$ & $\begin{array}{c}48.6(41.3,53.3) \\
(139)\end{array}$ \\
\hline P1 & $\begin{array}{c}41.1(31.3,50)^{\mathrm{g}} \\
(118)\end{array}$ & $\begin{array}{l}32.9(22.2,42.3)^{\mathrm{g}} \\
\quad(114)\end{array}$ & $\begin{array}{l}49(38.8,49) \\
(112)\end{array}$ & $\begin{array}{c}56.1(51.9,58.8) \\
(108)\end{array}$ & $\begin{array}{c}41.3(35.1,47.7)^{\mathrm{g}} \\
(107)\end{array}$ \\
\hline $\mathrm{P} 2$ & $\begin{array}{c}46.3(35,58.8)^{\mathrm{g}} \\
(62)\end{array}$ & $\begin{array}{l}33.6(25.4,40.9)^{\mathrm{g}} \\
\quad(60)\end{array}$ & $\begin{array}{c}46.5(36.8,58.3) \\
(59)\end{array}$ & $\begin{array}{c}55.9(53,58.6) \\
(57)\end{array}$ & $\begin{array}{c}36.3(26.6,36.3)^{g} \\
\quad(57)\end{array}$ \\
\hline P3 & $\begin{array}{c}51.3(45,61.7)^{\mathrm{g}} \\
(46)\end{array}$ & $\begin{array}{l}35(30.6,43.5)^{g} \\
(45)\end{array}$ & $\begin{array}{c}42.4(31.9,54.2) \\
(41)\end{array}$ & $\begin{array}{c}54.8(50.5,59.6) \\
(44)\end{array}$ & $\begin{array}{c}34.6(27.7,42.5)^{\mathrm{g}, \mathrm{h}} \\
\quad(44)\end{array}$ \\
\hline$p$ value $^{\mathrm{i}}$ & .0003 & $<.00001$ & .0200 & .8870 & $<.00001$ \\
\hline $\begin{array}{l}\text { b Brief COPE Sca } \\
{ }^{\mathrm{c}} \text { Optum SF-36v2 } \\
{ }^{\mathrm{d}} \text { Pre-P1 }=\text { Pre-Cu } \\
{ }^{\mathrm{e}} \text { Physical Compo } \\
{ }^{\mathrm{f}} \text { Mental Compon } \\
{ }^{\mathrm{g}} \text { Significantly dif } \\
{ }^{\mathrm{h}} \text { Significantly dif } \\
{ }^{\mathrm{i}} \text { Skillings-Mack }\end{array}$ & $\begin{array}{l}\text { culum Year One, P1 } \\
\text { cht Summary Scale } \\
\text { t Summary Scale } \\
\text { rent than Pre-P1 } \\
\text { rent than P1 }\end{array}$ & Irriculum Year One, P2 & rriculum Year Tw & $\begin{array}{l}\text { Itegy } \\
\text { Curriculum Ye }\end{array}$ & \\
\hline
\end{tabular}


American Journal of Pharmaceutical Education 2020; 84 (3) Article 7547.

Table 4. Correlation of Perceived Stress with Coping Strategies and Health-Related Quality of Life

\begin{tabular}{|c|c|c|c|c|}
\hline$\overline{r_{s}{ }^{a}}$ & PSS $^{b}$ Pre-P1 $^{c}(n=132)$ & $\operatorname{PSS~P1}^{\mathrm{c}}(\mathrm{n}=96)$ & $\operatorname{PSS~P2}^{\mathrm{c}}(\mathrm{n}=51)$ & $\operatorname{PSS~P3}^{\mathrm{c}}(\mathrm{n}=39)$ \\
\hline Maladaptive Coping Strategies ${ }^{\mathrm{d}}$ & 0.43 & 0.24 & 0.58 & 0.20 \\
\hline Adaptive Coping Strategies & 0.04 & 0.07 & -0.03 & -0.31 \\
\hline $\mathrm{PCS}^{\mathrm{e}}$ & 0.08 & -0.19 & -0.15 & -0.21 \\
\hline $\operatorname{MCS}^{\mathrm{f}}$ & -0.47 & -0.69 & -0.78 & -0.73 \\
\hline
\end{tabular}

${ }^{a}$ Spearman Rank Order Correlation. Small $<0.29$, Moderate, 0.30 0.49, Large $>0.5$

${ }^{\mathrm{b}}$ Perceived Stress Scale. Scores increase with increased perceived stress

${ }^{c}$ Pre-P1 = Pre-Curriculum Year One, P1=Curriculum Year One, P2=Curriculum Year Two, P3=Curriculum Year Three

${ }^{\mathrm{d}}$ Scores increase with increased use of the type of coping strategy

e Physical Component Summary Scale

${ }^{\mathrm{f}}$ Mental Component Summary Scale

mental health, and used more maladaptive coping strategies during the three pre-clinical years of the curriculum compared to levels reported at entry to pharmacy school. While the level of stress, mental health, and maladaptive coping during each successive year of the curriculum (P1-P3) was greater than students' mean level of stress on entry to pharmacy school, the magnitude of scores was similar across the three pre-clinical years, with the one exception of the mean MCS score in the P3 year being significantly lower than that in the P1 year. Increased stress exhibited moderate to large correlation with poorer MCS and greater use of maladaptive coping strategies. This second cohort was similar to the previously assessed earlier cohort in terms of demographics and observed trends in stress, MCS, and use of maladaptive coping strategies. Although curricular and resource changes were made at the school between the time of the two cohorts, these results demonstrate that program improvement to address stress and its impact is a complex and ongoing process. Notable results are discussed below.

The stress levels, as measured by PSS, worsened in our cohort as students progressed through the PharmD curriculum. This pattern of escalating stress levels from the P1 to the P3 year of the program was similar to what we observed in the previously reported cohort (classes of 2006 through 2012) and that in two other studies that examined stress levels by year in the PharmD curriculum. ${ }^{8,2,5}$ Median PSS10 scores in this study were remarkably similar (range from 35 to 51) to mean scores in other studies of pharmacy students using the PSS-10 (range 40 to 55 when those scores based on a $0-40$ range were converted to the $0-100$ scale used in our study). ${ }^{1,3,4}$ Only one study of students entering the first professional year of a two/four program reported a higher mean stress level (58.0) than our highest median PSS score (51.3 in the $\mathrm{P} 3$ year). ${ }^{6}$ Stress scores in $\mathrm{P} 2$ and $\mathrm{P} 3$ years approached levels considered worthy of significant intervention, ie, scores that would be perceived as a very high health concern by a social work agency (above 52 on $0-100$ scale) and in the upper range of moderate stress by an employee assistance program (above 50 on $0-100$ scale). ${ }^{18,19}$
Potential causes of increasing stress related to the PharmD program may include rigor of the curriculum, financial burden of schooling, fear of debt, and future job uncertainty. An additional contributor to stress could be uncertainty and competition related to obtaining a residency position. In 2017, ASHP reported a 67\% match rate nationally for postgraduate year 1 residency positions, which translated to 1925 applicants that did not obtain a residency position. ${ }^{20}$ This gap can contribute to increased stress for students, especially at our institution where a high percentage $(65 \%-80 \%)$ of our graduates seek postgraduate residency opportunities.

Student use of maladaptive coping strategies in all three of the pre-clinical years of the PharmD program was more than twice the level of that at pharmacy school entry. Although adaptive coping strategies did decline over the course of the PharmD program, students' reported use of adaptive coping measures was always greater than their use of maladaptive coping strategies. The magnitude and balance of maladaptive and adaptive coping strategies were similar to that observed in the previously reported cohort. The MCS scores declined steadily in each of the three preclinical years of the curriculum, and the MCS score of P3 students was 14 points below the score of P1 students at orientation. This difference is more than twice that considered as clinically significant ( 5 points) $>$ The level of MCS in each of the three pre-clinical years of the PharmD curriculum was lower (ie, worse mental health score) than the cutoff score for major depression or dysthymia (42.0). ${ }^{21}$ The pattern of declining MCS and the magnitude of MCS levels were similar to those observed in the previously reported cohort. As in the first cohort study, increased stress was negatively correlated with MCS scores in students across all academic years. This finding is also consistent with other published results regarding stress in PharmD students. $^{22,23}$ A moderate to large correlation between increased stress and increased use of maladaptive coping strategies was detected in both cohorts, although it was less consistent in the current cohort (P1 year orientation and $\mathrm{P} 2$ year only) than in the prior cohort. Notably, unlike the prior 


\section{American Journal of Pharmaceutical Education 2020; 84 (3) Article 7547.}

cohort, we did observe a moderate correlation between increased stress and decreased usage of adaptive coping strategies in the P3 year of the current cohort.

The results of our study add to the literature suggesting that additional work needs to be done in recognizing stress and coping strategies among pharmacy students and, that more importantly, creative solutions are needed to mitigate the levels of stress among students, especially in later years of the PharmD program. The National Academy of Medicine recognizes that in order to address stress and burnout among health professionals, a multi-pronged approach is needed. Additionally, they have urged educators in the health professions to take appropriate steps to mitigate student stress. ${ }^{24}$ NAM has stated that organizations must address organizational culture; promote health and wellness; align supportive policies; support students, trainees, and professionals in the practice setting; and create and train positive role models. Our observation of the consistent and large correlation of increased stress with increased use of maladaptive coping stratgies and markedly reduced MCS scores is concerning and indicates that measuring only students' stress levels does not provide enough information to identify solutions and preventative measures. Furthermore, perceived stress may vary across student groups. Students may perceive stress differently according to their age (eg, students younger or older than traditional professional school age of 22-26 years reported greater stress), gender (eg, female students experienced greater stress than male students), and ethnic groups (eg, Asian students experienced greater stress than Caucasian students). ${ }^{25,26}$ Therefore, faculty and staff education regarding these potentially high-risk groups may be warranted. Institutions should seek strategies to not only identify individuals at high risk, but also to provide potential resources for care and remove barriers to care.

Potential strategies for reducing stress and improving coping skills among students may include one or more of the following, which also address many of the NAM recommendations and have been implemented at the UC San Diego Skaggs School of Pharmacy and Pharmaceutical Sciences (SSPPS). Schools are encouraged to work closely with the Counseling and Psychological Services (or similar offices) to ensure that the process of referring distressed students to a provider is efficient. A liaison who is available for quick consultations by the Office of Student Affairs may be helpful. Additionally, campuses can launch a program such as the weekly drop-in "Let's Talk" program at our school, which is conducted by a licensed therapist. Students can drop-in to discuss issues such as stress, sleep issues, or anxiety. This therapist acts as a conduit to Counseling and Psychological Services should the student require more of an intervention. To help reduce academic stress, a peer-to peer tutoring program was implemented for students experiencing marginal or poor course performance. Students who previously achieved honors in the course are selected as tutors and the school pays for up to four to six hours of tutoring per course per student. Wellness offerings and events may also be incorporated to reduce stress and improve coping skills. Some activities that have been implemented at SSPPS include therapy dog sessions, a quarterly lifestyle and wellness seminar series that focuses on healthy lifestyle habits, stress management, prevention of burnout, mindfulness and well-being for health professional students, and recreational team-building activities. These quarterly wellness events continue to be well attended, with students providing input on featured topics. In response to these study outcomes, SSPPS initiated a robust curricular review and a residency and postgraduate preparedness program. Recognizing that contributors to stress are multifactorial and may not necessarily be caused by academic rigor or performance is also important. For example, SSPPS has implemented training to improve students' debt management skills and expectations, which may be helpful but does not offset the reality of the high cost of pharmacy education. The implementation of the resources and programs above specifically to target student stress began in 2016 in part because of the results from our initial study. The current study captures student data through the P1 year for the Class of 2017, and the impact of these resources and programs on students' quality of life, stressors, and coping strategies has not yet been assessed. In the academic year of 2016-2017, SSPPS launched an assessment plan based on this study that includes a quality of life survey that is administered to all students. Students are surveyed at baseline (during P1 orientation) and at the end of each P1, P2, P3, and P4 years. The survey is composed of demographic information, the Brief COPE scale, the Perceived Stress Scale, and the SF-12 scale. All students are required to participate and the survey results are reported on an aggregate level for programmatic improvement purposes.

Several limitations should be considered when interpreting the results of this study. Results may not be generalizable to other pharmacy schools because students, curricula, and programmatic structure differ appreciably. Responses in this study were from a four-year postgraduate PharmD program that includes a joint medical and pharmacy school basic science curriculum in the P2 year. Having this combined curriculum may add additional stress that is not experienced by students in other pharmacy schools for a variety of reasons (eg, large combined class sizes, change in examination format). Participation in this study was voluntary and involved students completing assessments three times per year over three years. Not all students chose to participate and some students dropped out of the study over time, resulting in a less than ideal sample 


\section{American Journal of Pharmaceutical Education 2020; 84 (3) Article 7547.}

size of students participating throughout their enrollment. The demographic characteristics of dropouts were similar to those of other study subjects, however, it is not known whether our sample was truly representative of our student body. Also, students who volunteered for the study and/or stopped participating prior to the final assessment may have had higher or lower perceived levels of stress than those who chose not to participate or participated for the entire study. This limitation underscores the importance of implementing required assessments as SSPPS did beginning in the 2016-2017 academic year.

\section{CONCLUSION}

This study revealed a very similar pattern of increasing stress, increasing usage of maladaptive coping strategies, and declining MCS across the three pre-clinical years of the PharmD program for this second cohort of students as we had observed in a previous cohort five years earlier. The levels of stress identified approached benchmarks considered worthy of significant interventions. Notably, the level of MCS was lower than that used as a cut-off level when screening for major depression or dysthymia, which is concerning. A multi-prong approach to implementing effective stress reduction solutions and assessing the affect of these solutions on students' stress, coping mechanisms, and HRQOL is needed. The impact of a wide range of targeted actions recently taken by the school to address stress will be reflected in the next five-year cohort, which will include all students so that results are representative of the entire study body.

\section{REFERENCES}

1. Chisholm-Burns MA, Spivey CA, Jaeger MC, Williams J. Associations between pharmacy students' attitudes toward debt, stress, and student loans. Am J Pharm Educ. 2017;81(7):5918. doi: 10.5688/ajpe8175918.

2. Garber MC. Exercise as a stress coping mechanism in a pharmacy student population. Am J Pharm Educ. 2017; 81(3):50. doi: 10.5688/ ajpe 81350 .

3. Ip EJ, Nguyen K, Shah BM, Doroudgar S, Bidwal MK.

Motivations and predictors of cheating in pharmacy school. Am J

Pharm Educ. 2016;80(8):133. doi:10.5688/ajpe808133

4. Beall JW, DeHart RM, Riggs RM, Hensley J. Perceived stress, stressors, and coping mechanisms among doctor of pharmacy students. Pharmacy (Basel). 2015;3(4):344-354. doi: 10.3390/pharmacy3040344. 5. Votta RJ, Benau EM. Predictors of stress in doctor of pharmacy students: results from a nationwide survey. Curr Pharm Teach Learn. 2013;5(5):365-372.

6. Geslani GP, Gaebelein CJ. Perceived stress, stressors, and mental distress among doctor of pharmacy students. Soc Behav Pers. 2013;41(9):1457-1468.

7. Maynor LM, Carbonara G. Perceived stress, academic self concept, and coping strategies of pharmacy students. Int J Pharm Educ Pract. 2012;9(1):1-9.

8. Hirsch JD, Do AH, Hollenbach KA, Manoguerra AS, Adler DS. Students' health-related quality of life across the preclinical pharmacy curriculum. Am J Pharm Educ. 2009;73(8):147.
9. American Association of Colleges of Pharmacy. Report of the 2016-2017 Student Affairs Standing Committee. https:// www.ncbi.nlm.nih.gov/pmc/articles/PMC5701335/. Accessed March 7, 2020.

10. Accreditation Council for Pharmacy Education. Accreditation Standards and Key Elements for the Professional Program in Leading to the Doctor of Pharmacy Degree ("Standards 2016"). https:// www.acpe-accredit.org/pdf/Standards2016FINAL.pdf. Accessed March 7, 2020.

11. Cohen S, Kamarck T, Mermelstein R. A global measure of perceived stress. J Health Soc Behav. 1983;24:385-396.

12. Carver CS, Scheier MF, Weintraub JK. Assessing coping strategies: a theoretically based approach. J Personality Social Psychol. 1989;56:267-283.

13. Carver CS. You want to measure coping but your protocol's too long: consider the brief COPE. Int J Behav Med. 1997;4:91-100.

14. Meyer B. Coping with severe mental illness: relations of the brief COPE with symptoms, functioning and well-being. $J$

Psychopathology Behav Assessment. 2001;23:265-277.

15. Optum. SF-36v2 Health Survey. https://www.optum.com/ solutions/life-sciences/answer-research/patient-insights/sf-healthsurveys/sf-36v2-health-survey.html. Accessed March 7, 2020. 16. Norman GR, Sloan JA, Wyrwich KW. The truly remarkable universality of half a standard deviation: confirmation through another look. Expert Review of Pharmacoeconomics \& Outcomes Research, 2004;4:5,581-585.

17. Cohen J, Cohen P, West SG, Aiken LS. Applied Multiple Regression/Correlation Analysis for the Behavioral Sciences. $2^{\text {nd }}$ edition. 2003. Lawrence Erlbaum Associates: Hillsdale, NJ. 18. State of New Hamshire Employee Assistance Program. Perceived Stress Scale. https://das.nh.gov/wellness/docs/percieved\% 20stress\%20scale.pdf. Accessed March 7, 2020.

19. Milwaukee Child Welfare Partnership. Perceived Stress Scale, PSS. https:/uwm.edu/mcwp/wp-content/uploads/sites/337/2015/12/ Perceived-Stress-Scale12-1-14.pdf. Accessed March 7, 2020. 20. American Society of Health-System Pharmacists. Residency Matching Program. https://natmatch.com/ashprmp/stats/ 2018applstats.pdf. Accessed March 7, 2020.

21. McCalli NT, Parks P, Smith K, et al. The prevalence of major depression or dysthymia among aged Medicare fee-for-service beneficiaries. Int J Geriatric Psychiatry. 2002;17:557-565. 22. Marshall LL, Allison A, Nykamp D, Lanke S. Perceived stress and quality of life among doctor of pharmacy students. Am J Pharm Educ. 2008;72(6):Article 137.

23. Gupchup GV, Borrego ME, Niranjan K. The impact of studentlife stress on health related quality of life among doctor of pharmacy students. College Student Journal. 2004;38(2):292-301. 24. National Academy of Medicine. A multifaceted systems approach to addressing stress within health professions education and beyond. https://nam.edu/wp-content/uploads/2017/01/MultifactedSystems-Approach-to-Addressing-Stress-Within-Health-

Professions-Education-and-Beyond.pdf. Accessed March 7, 2020. 25. Beall JW, DeHart RM, Riggs RM, Hensley J. Perceived stress, stressors, and coping mechanisms among doctor of pharmacy students. Pharmacy. 2015;3:344-354.

26. Votta RJ, Benau EM. Predictors of stress in doctor of pharmacy students: results from a natiowide survey. Curr Pharm Teach Learn. 2013,5:365-372. 